\title{
On the Role of Nonverbal Communication in Li Ziqi's Videos in Intercultural Communication
}

\author{
Qinpei Fan* \\ No. 100 Shuifeng Road, Shanghai Publishing and Printing College, Shanghai, China \\ *Corresponding author. Email: 39312543@qq.com
}

\begin{abstract}
This article intends to analyze the role of non-verbal communication in cross-cultural communication from the four types of non-verbal communication in Li Ziqi's videos: 1. Kinesics: body behaviors produced by speakers; 2 . Proxemics: uses of spatial setting by speakers; 3. Sound; 4. Chronemics: use of time; 5. Costume. The heated overseas broadcast of Li Ziqi's videos fully illustrates the importance of non-verbal communication in cross-cultural communication, and opens up flexible and diverse non-verbal cross-cultural communication methods.
\end{abstract}

Keywords: Kinesics, Proxemics, Soun, Chronemics, Costume.

\section{INTRODUCTION}

Li Ziqi puts videos of her life in the mountains of Sichuan on the Internet, and the shooting time span is very large, which makes the record closer to the essence. Because of the exquisite composition and leisurely pace of life, her video is more like an idyllic documentary, which has been sought after by countless people. From making bamboo furniture, four treasures of the study, clothes, to roasting whole lamb, making wine, bread kilns, brewing soy sauce... Li Ziqi's antiquity pastoral videos circle fans from all over the world, and are known as successful cases of cross-cultural communication. At present, China's practice of cross-cultural communication abroad is becoming more and more extensive. The phenomenon-level cross-cultural communication effect achieved by Li Ziqi's video is a successful example of Chinese culture going global, and it has important reference and significance for Chinese culture's external communication. The video of Li Ziqi has become a window to show the image of China, which has raised overseas people's attention to Chinese culture to a whole new level, and has important reference significance for China to build its national image. In this intercultural communication process, the dissemination of non-verbal communication content is an important factor in the success of her videos.

\section{NONVERBAL COMMUNICATION}

"Nonverbal communication is a way of communication without words. [1]" For human beings, nonverbal communication is the specific use of non-verbal means to communicate with each other. It is the interaction that is carried out by our bodies, gestures, postures, everything except the actual words we apply in our communication, such as the look on our face, the way we dress, the time we consume to communicate, the distance we keep between each other, sounds or even silence. Four categories of Nonverbal messages in Li Ziqi's videos are to be analyzed in this article: 1 . Kinesics: body behaviors produced by speakers; 2 . Space: uses of spatial setting by speakers; 3 . Sound 4. Chronemics: use of time; and 5. Costume: use of dress.

\subsection{Kinesics: Body Behaviors Produced by Speakers}

Kinesics is the nonverbal behavior related to movement, either of parts of the body, or of the body as a whole, including facial expressions, gestures, postures, eye contact, etc. First, facial expression serves as an efficient way to carry out nonverbal communication. The face and eyes carry the most expressive types of body languages. Second, gestures are another important aspect of body language. 'Gestures can be emblems or symbols ("V" for victory), illustrators (police officer's hand held up to stop traffic), regulators (glancing at your watch to signal that you are in a 
hurry), or affect displays (a person's face turns red with embarrassment).[2]' Third, posture, the way someone stands, sits, or walks, can send positive or negative nonverbal messages. Posture can convey self-confidence, status, and interest. Confident people like Li Ziqi generally have a relaxed posture yet stand erect and walk with assurance.

In the video "The Life of Cotton", Li Ziqi and her grandmother make a tool for popping cotton. After the production is completed, she makes quilts for her grandmother and kennels for her dog. In many videos, grandmother accompanies Li Ziqi: sometimes she helps trim vegetables to be used for cooking later by Liziqi and sometimes covers Li Ziqi with a blanket when she falls asleep... whatever she does for Li Ziqi, there is always calm and happiness on her face, her movements being unhurried and gentle. When Li Ziqi explores the scenes in the mountain the dog accompanies and safeguards her; When Liziqi sits and doing housework, it is around rubbing her feet... The affection between the family members is naturally revealed, which arouses the emotional resonance of overseas audiences. At the end of each food video, most of the time Li Ziqi and her grandma are sitting facing each other while chatting and eating, or sometimes Li Ziqi shares food with friends and neighbors. The audience doesn't understand the Sichuan dialect at all. But the body language of Li Ziqi and her grandmother: picking up food for each other and toasting around the stove naturally arouses our nostalgia for family affection, which is a kind of emotional comfort.

\subsection{Proxemics: Uses of Spatial Setting by Speakers}

Communicating through the use of space is known as proxemics. The language of space is powerful. Traditional research on space is usually about:" How close can we get to people." or on "How distant should we be?" The physical distance between people when they are interacting, as well as territorial space, is strongly influenced by culture. In the videos, there are few people, but there are beautiful mountain trails, small courtyards with fragrant melons and fruits, rice fields, bamboo forests, mountain roads, streams, and cooking smoke. Li Ziqi's life is far away from the city and crowd, but is so close to nature. And it is this closeness with nature that is popular with audience all around the world.

In addition to the external space that is like Chinese landscape painting, the interior of $\mathrm{Li}$ Ziqi's own courtyard is also filled with the profound Chinese pastoral beauty: small quadrangle, bridge, pavilion, swing, flowers, plants, fruits and vegetables, and even a fish pond. Its spatial setting resembles a small private garden. The various scenes in the video are perfect as non-verbal symbols of cultural transmission. It is in these kinds of poetic scenes that Li Ziqi personally tailors, sews and insists on wearing traditional clothes. She presents traditional Chinese craftsmanship in a small farmhouse that is built and perfected by her hands, full of vegetables and fruits of various colors. In it, she is indulged in peach blossom wine making, silkworm breeding, silk harvesting, Shu embroidery, hand-made paper, movable type printing, hand-made pen, ink, paper and inkstone... The craftsmanship that carry the ancient Chinese traditional culture are completely alien to overseas audiences and full of exotic customs. The video "hanging dried persimmons" presents picking persimmons, drying persimmons, baskets, hemp rope, and stove warming tea, etc. These non-verbal symbols (baskets, hemp rope, stove...) and the spatial setting (a small farmhouse under snow in the mountains) allow overseas audiences to get the great satisfaction of prying into foreign cultures that are different from their own cultures.

\subsection{Sound}

The background music of the video is not lyrics, but melodious and graceful pure music, just to set off the beautiful scenery and quiet life. In the video, there is the natural sound of rain, birdsong, gurgling of the stream... and also sounds from human beings: Li Ziqi picked grapes and tomatoes and thus makes the sound of broken branches, cut vegetables and meat, the crackling sound of fire out of firewood in the stove, a gurgling sound issued from the pot of meat being stewed. All of these sounds, together, become unique Chinese cultural characteristics of non-verbal symbols, spread the charm of China, as well as heal audience from different cultural backgrounds of the world.

\subsection{Chronemics}

Attitudes toward time (Chronemics) vary from culture to culture. Two kinds of time are normally discussed. One is objective time, which involves clocks and calendars; the other is subjective time, which relates to how an individual perceives time.

First, in the perspective of objective time, traditional Chinese culture advocates a cyclic view of time. It is reflected in the diet in accordance with the season, with four distinct seasons, and processed and produced according to the mature plants of the season. Eating according to the season and eating at the right time are fine traditions of Chinese food culture. It is a concrete manifestation of the Chinese philosophy of "the harmony between man and nature". It also embodies the superb survival wisdom of the Chinese people and reflects China's unique health culture.

Second, in the perspective of objective time, time is so personal for individuals and all of us perceive and treat it in a manner that can express our character. As for 
people from one group (with the same cultural background), the way we use time can provide valuable clues to how we value and respond to time. In the videos, Li Ziqi takes us to experience the slow way of life: stay away from industry and follow nature. In "It's a Farmer's Busy Harvesting Grain", the picture shows the process of a seed from germinating, growing, harvesting to white rice in a bowl; in "Corn", Li Ziqi shows the process of hoeing, loosening the soil, planting and harvesting corn seeds and ultimately into tortillas. Different from Western industrial farming, Li Ziqi's rice cultivation is artificial cultivation. The audience follows the cultivators to experience the hardships of "sweats dripping down the soil" and the change of seasons: the rice is slowly growing in the sunshine, dew, rain, and wind until the we finally enjoy the joy of harvest together with Li Ziqi. White rice is paired with a handful of meat, a simple match, but the audience can feel the fullness and sweetness of each grain of rice in the bowl from out of the screen. It takes a lot of time to witness the growth of each step of the rice. Affection for every grain of rice is cultivated gradually through time. In addition to witnessing the germination of seeds and the growth of seedlings, the video also deliberately or unintentionally took the audience to experience the sunrise and sunset, the stream running and the flowers blooming: the audience followed Li Ziqi's footsteps through the mountains and forests, past lakes and snow and capped mountains. Through Li Ziqi's video, overseas audiences have experienced the fairyland-like rural countryside and beautiful natural scenery in China Sichuan Province. In this process, the audience followed Li Ziqi, experiencing every minute and every second in the harmonious relationship between man and nature, and was relieved of stress. The popularity of Li Ziqi's videos prove the fact that to live in a slow way (that means to live naturally instead of in an efficient way) is cherished by many people from various cultural backgrounds.

\subsection{Costume}

Costumes are non-verbal symbols that are relatively superficial and easy to observe in cross-cultural communication. Costumes reflect people's ideology, social customs, moral fashion and aesthetic tastes in a particular era. In the video, Li Ziqi's costumes include coarse linen, cloak, and Hanfu such as plain blouses, underskirts, jacket skirts, and cloaks, as well as cheongsam that perfectly demonstrates the unique temperament of Chinese women. Her clothes are simple in color, mostly light-colored, made of cotton, linen and silk, and feel comfortable and light. Li Ziqi's clothing highlights the human spirit and temperament rather than the curve of the human body, but it will inadvertently show the curve of the human body, with a mysterious beauty.
In the video of "Kumiss Making", Li Ziqi wears a red shawl and rides on the back of a horse. Under the shawl is a blue ethnic style slim dress with her hair tied up high. A lady and a horse running in the mountains, looks quite chivalrous. In the process of making kumiss, she changes into a cotton-padded coat that was easy to move, and that gives her a bit of homely gentleness. In the "Shu Embroidery" video, she wears a light blue cheongsam on the inside and a green sweater on the outside. When her hair spreads out naturally, She immersed in embroidery, showing the gentleness of a southern woman.

\section{CONCLUSION}

In Li Ziqi's videos, the audience feels the power of nonverbal signs, which can cross national boundaries, break through language barriers, and realize the transmission of meaning. Li Ziqi's video is loyal to life, presenting the culture of clothing, food, housing and transportation with Chinese characteristics to audiences of different cultural backgrounds, and tells the real Chinese story. In Liziqi's videos, she seldom talks. But the videos communicate more than the words we speak through such nonverbal communication means as kinesics, proxemics, sound chronemics and costume.

By using non-verbal symbols, Li Ziqi's short videos explore a unique narrative mode of Chinese stories, namely daily narratives, allowing the audience to subtly accept the values and meanings conveyed by the story, and avoid the audience's aversion to the missionary and educational output that is easily brought by the narrative way.

Through the daily narratives, on the one hand, $\mathrm{Li}$ Ziqi showed the diligence and intelligence of the Chinese and conquered overseas people with her creative power. Li Ziqi presents an independent, beautiful and kind-hearted, industrious and intelligent perfect oriental female image. The mainstream Western values focus on the realization of individualistic values, advocating the realization of personal dreams through personal hard work and unremitting pursuit. Therefore, Li Ziqi's independence and the courage to pursue personal values can not only inspire contemporary Chinese youth, but also conform to the values of the vast overseas people.

On the other hand, the cross-cultural communication of Li Ziqi's video shows the essence of Chinese culture and the unique charm of Chinese culture to the western audience. The interpretation of the traditional Chinese lifestyle in the video shows Western audiences the traditional Chinese farming lifestyle: working at sunrise, returning at sunset, self-sufficiency, a lifestyle of harmonious coexistence between man and nature, revealing vividly Eastern culture and Eastern civilization. In this way, Western people have more 
knowledge and understanding of Eastern culture and Eastern civilization.

\section{REFERENCES}

[1] Malandro, Barker, et al., Nonverbal Communication (2nd edition), Rowley: Newbery Award Records, 1989
[2] Lillian H Chaney, Intercultural Business Communication (6th edition), Beijing: China Renmin University Press, 2015. 